\title{
The world of the drug addict
}

\section{O mundo do drogadicto}

Gilberto Di Petta ${ }^{1}$

\begin{abstract}
Drug addiction undermines intentional consciousness. Whereas in normal consciousness we have a fluid intentionality and our common sense is the obviously pre-reflexive result of this situation, under the influence of a drug intoxication we lose this intentional stability and, as a consequence, suffer from a kind of intentional instability, which we can refer to with the term floating world. This floating world is characterized by splitting, vibration and a multiplication of images which can be both sequential or overlapping. On the other hand, following chronic drug assumption, we have a sort of an intentional dramatic capture or seizure of the world, which we can call frozen world. Lived time, space, the body and other existential parameters differ enormously in these two contrasting ways of being. The crisis of the temporal-spatial vortex eventually and inevitably leads to the blow of the void (le coup de vide): the experience of unreality or no self-experience. The total collapse of the world is the common final result of the breaking down of the temporal and spatial structure of Dasein.
\end{abstract}

Keywords: Life-world; Addiction; Consciousness; Intentionality; Lived time; Lived space

\section{Resumo}

A dependência de drogas compromete a consciência intencional. Na consciência normal, observa-se uma intencionalidade fluida, sendo a realidade compartilhada o resultado préreflexivo óbvio desta situação. Sob o efeito da intoxicação por drogas, no entanto, perdese esta estabilidade intencional e, consequentemente, padece-se de uma espécie de instabilidade intencional, que podemos denominar mundo flutuante. Este mundo flutuante é caracterizado pela desagregação e, vibração e por uma multiplicação de imagens que podem ser sequenciais ou sobrepostas. Por outro lado, como consequência do uso crônico de drogas, observa-se uma captura ou tomada intencional dramática do mundo, que podemos chamar de mundo congelado. O tempo, espaço e corpo vividos, assim como outros parâmetros existenciais, diferem enormemente nestes dois modos-de-ser 
contrastantes. A crise do turbilhão temporo-espacial leva final e inevitavelmente à queda no vazio (le coup de vide): à experiência de irrealidade ou ausência da experiência de si mesmo. O colapso total do mundo é o resultado final comum da fratura da estrutura temporal e espacial do Dasein.

Palavras-chave: Mundo vivido; Adicção; Consciência; Intencionalidade; Tempo vivido; Espaço vivido

${ }^{1}$ MD, Psychiatrist and Neurologist; S. Maria delle Grazie Hospital, Female Prison, Addiction Centre Consultant. E-mail: gilbertodipetta@alice.it

Received: $1 / 19 / 2017$

Accepted: 2/2/2017

Psicopatologia Fenomenológica Contemporânea, 2017;6(1):15-36 


\section{Drifting/on a sea of forgotten teardrops}

On a lifeboat/Sailing for/Your love

Sailing home (home)/Drifting

On a sea of old heartbreaks/On a lifeboat

Sailing for/ Your love

Sailing home (sailing home).

Jimi Hendrix

\section{The phenomenological approach}

What sense is there at this moment in time in proposing a phenomenological approach to addiction, which is such a varied psychopathological and human condition, when empirical research is centred entirely on the collection, analysis and elaboration of measurable and verifiable models? The psychosocial hypotheses of the last century, which supplied different interpretations of the social context and the addictive personality, seem to have lost their bite. No psychosocial model is able to help explain the tremendous diffusion of various forms of drug abuse among the general population. Both the models of family and of society have undergone a great change in the last fifty years, however, there is no psychosocial parameter that is closely linked in any way to the explosion and multiplication of drug abuse. Furthermore, the psychosocial models have been lacking in any attempt to set up therapeutic protocols which aim at recovering the individual and helping him to overcome drug abuse. It has not been possible to repeat the success achieved by the neurobiological approach, which substitutes one drug with another, e.g. heroin-methadone, in the treatment of drug abuse. The study of receptors and ligands has not kept up with the incredible proliferation of synthetic drugs, for which, at this time, no substitute exists. The spread in the abuse of nonpharmacological additives has made the use of drugs which could contrast the effect of each substance virtually impossible. The typical present-day drug addict is a polyabuser, in whose brain it is practically impossible to pinpoint where the behavioural and neuropsychic effects of any single drug take place. Nowadays the world of addiction is extremely differentiated with synthetic and recreational substances being used alongside the more traditional drugs. Other addictions have come to exist besides drug addiction - gambling, shopping, sex, the Internet, etc. Eating disorders could also be considered to some extent as being a form of addiction. It is obvious that in the field of neuro-psychiatry the effects of chemical agents 
like drugs is completely different from behavioural disorders caused by gambling or the Internet. The psychiatric effect of drugs has been compared to synthetic psychoses which are considered to be exogenic psychosis having a very different psycho-pathological structure from the schizophrenic and affective psychosis of more standard psychoses.

The question of the phenomenological approach should be explained. The phenomenological approach, due to its inclination to grasp the intrinsic nature of phenomena, tends to form a common denominator which is in opposition to the proliferation of normal addictive behaviour and is a sort of typical, a-priori way of being-in-the-world of the addicted person, independently of a whole series of differential factors (personality, chemical or behavioural addiction, psychiatric complications). Phenomenology attempts to understand the "how" of each phenomenon, that is the way in which it happens independently of its causes. For the doctor a profound understanding of the way in which the phenomenon of addiction is formed represents a step into the patient's world. It allows the doctor to work together with his patient towards a better understanding of the patient's problems and thus clears the way for successful treatment. This may seem rather simplistic when compared to the approach of empirical research which is very careful to analyse and elaborate all the possible variables. However, having the chance to view a unitary perspective is a great help since it allows the doctor to have an immediate overall picture, and this is especially useful when meeting the patients since the characteristic of these patients, which is based entirely on "all and now", certainly does not provide much time for the working out of a therapeutic relationship. If the doctor manages to break through the patient's "addictive bubble" in the first meeting, he will then be able in some measure to appreciate the patient's intentionality. In turn this will allow the doctor to help steer his patient away from the polarization of his intentionality towards the object of his addiction, thus setting up the premise for a therapeutic relationship. When the doctor first meets the patient the most important thing for him is to achieve something on which to build up a contact with his patient from the very beginning rather than focus on the neurobiological determiners and the personological configurations of the patient. Because the addict's world is a purely sensorial world based primarily on perception any attempt at a more rational approach is not likely to prove successful. Any dropping out from the treatment at this stage would have dramatically negative consequences for the patient, both physically and psycho-socially. The more an addict becomes socially integrated, the less apparent are those elements that derive from social degradation and the 
consideration of being a social outcast. Thus the catastrophic downward curve of their existence is reflected and dangerously amplified in their position in society.

Towards the end of their existential journey and of their drug addiction the lives of people, who were apparently quite different beforehand, flow together into a common dimension of loss. This is a sort of common destiny. Any initial difference disappears and what emerges is the phenomenon in its common denominator. The collapse of existence, cleared of its a-priori formal structures of space and time, becomes evident. The knowledge of the constitution of "the world-of-life" of the addict is fundamental not only for any transformative approach that attempts to tackle the problem, but also for any attempt to reinstate the treatment, the world project, the constitution of the other. In 1927 Heidegger, in Being and Time, defined treatment (Sorge) as a fundamental existential dimension, or rather as an activity characterised by man's being-in-the-world. According to Heidegger man is man only if he takes care of something or someone or of himself. The "world-project" is built around the concept of taking care, or the reaction to the "being-thrown-into-the-world" by being born, with the differing future prospect which allows the individual to express his own individuality. The anthropological-phenomenological definition of the addict can begin from a context which is the exact opposite of this: negligence, the loss of care and as a result the loss of a world-project built around the treatment. The phenomenological approach is particularly successful when it has something on which to build up on. Giving positive results when it can begin from a relationship with those patients who are particularly unwilling to enter into any kind of relationship whatsoever, having been continuously rejected and having become accustomed to a nomadic existence, which has profoundly undermined their own personality.

\section{The addictive world}

It would be wrong to consider the complexity of the addictive experience exclusively in psychological terms (intrapsychic and interpersonal conflict) or, as is recently becoming more common, exclusively in neurobiological terms (circuits of pleasure). The phenomenological approach extends above all to a horizon of an anthropological nature (Weiszaecker, 1967, 1968), interpreting the addictive phenomenon as a result of the deep crisis of the presence that has unhinged the being-in-the-world of postmodern man. Drugs and other narcotic substances have in fact been used since human life began on the planet, 
accompanying man in his rituals for sacred occurrences, when he went to war, in love and during dionysiac frenzies. The fact that these substances, which have been present for thousands of years, have represented a medical epidemiological problem only since the last decades of the last century implies that the cultural ritualisation of their use is no longer applicable. This change has occurred at the same time as the development of techniques of synthesis of those drugs and of the explosion in mass communication. Today we encounter human beings who have lost their defining personalities, beings that are simply either integrated or disintegrated, beings who are either "in" or "out", inhabiting vagabond worlds, living clandestine lives, wherever they are and whatever they do remaining forever transitory, temporary, fragments of lived life and consciousness:- when the doctor comes face to face with them, he too is forced to become a wanderer, without any roots, almost obliged to be as much an interpreter of postmodern restlessness as his patients.

There is an invisible thread that, on the edge of nothingness, ties together the passion for drugs/drug abuse addiction and lived experiences like boredom (Noia, Langweiligkeit, Spleen), emptiness, angst and pervasive and intense anger (Verstimmung, Hubris): these features constitute both the psycho-pathology of the addict as a man living on the edge and unmistakable features found in contemporary philosophy (Heidegger, Sartre, Camus) and modern literature (Baudelaire, Musil, Joyce, Kafka). Mythical heroes of the generations belonging to the second half of the twentieth century - short-lived bright stars like James Dean, Jim Morrison, Kurt Cobain, all of whom embodied the impossibility/incapacity/inability of living their own not-to-be-found dimension, losing their lives at the very moment of their maximum, yet still immature, splendour. This balancing on the edge of the abyss connects, albeit from a distance and through the deformed effect of the reproducibility of the masses, the existence of drug addicts to the tragic destinies of figures like Keats, Shelley, Byron or Werther and Ortis, or Michaelstaedter, the bohemians and the scapigliati who experienced the fin de siècle weariness of over one hundred years ago, like our own Corazzini, Campana, Gozzano. All figures who have left us, both in their works and in the example of their short lives and their untimely deaths on the threshold of adulthood, the tragic sense of their inability to adapt to the modern world.

With the final sunset over both the rural and industrial world, the traditional cities which had been the historical framework of modern industrial and bourgeois civilisation, gave way to the infinite series of no man's lands that characterise modern cities and their 
outskirts. The current metropolitan topos is by its own definition a "nowhere" - a discontinuous and confused untidy succession of abandoned postindustrial wasteland, shopping centres, areas which are out-of-bounds and delimited, without history or sense. These places have no sense of meeting or of relationships between people, no cafés or places to walk and talk, no love or death. This is the background where the drug addict unequivocally realizes the figure of being-in-the-crisis as being-in-the-wreck or being-innothingness. In the heart of darkness of one of the deepest holes of contemporary nihilism the addict's existence might represent the place where the last battle is being fought to save all that makes man what he is, without all the historical encrustations on which the traditional idea of being-man were founded, and which have gradually been abandoned.

The first generation that embraced the consumption style of the heroin addict emerged in the west in the 1960s and 1970s. The failure of the youth movement's demonstrations, the subversive terrorist acts committed by extremists together with the return to a quiet bourgeois existence of many of the instigators of the revolutionary movement provided the ex-hippies with an alibi to completely destroy themselves. In this way opiates/narcotics met the need to alleviate the pain and anger of all those who had experienced the "season of illusions" and witnessed the failure of social reform and the consequent return to selfish interests and conformity. The world that had restored bourgeois ideals and forced them on the survivors of a counter-culture could not be accepted. Thus, needles, spoons, distilled water and lemon became the instruments of a rite of passage. The first time it was normal for someone else to administer the drugs, thereafter you would do it on your own. Pulling your belt tightly round your arm with your teeth, passing the needle or "sword" from one to another for a shot, you found yourself on the threshold of a new and fantastic discovery. The whole world became indifferent and you became indifferent to the progressive and unstoppable deconstruction and degradation of your own life. Today almost no-one from this first generation is still alive. Nearly all have succumbed to overdoses or AIDS .

What else remains for adolescents today apart from the noisy silence that fills up the boring everyday routine of adults? The night. How is night-time experienced? How are its spaces organised? How are those empty intervening metropolitan spaces filled? Or rather, how do all those needs/requests that are suppressed by everyday culture express themselves? Who are the figures, the characters, and what processes do they set off, for example in the world of nightclubs some of which are referred to in slang as being borderline, because they 
are the home of extreme on-the-edge effects? What are, then, the behavioural combinations or the experiential, symptomatological and psychopathological clusters that emerge from the miscellany of these chronically a-structured personalities, trapped in a sort of continuous present? All of this is associated with a vision of one's own life as being ensnared in the instant of an atemporal present, where nothing has any meaning other than the emergent moment that is, compared to what is continually being taken away from the senses because it is disappearing; where one's own life is seen as being separated from any working objective or pretext for responsibility; and where the only sense/sensation/feeling that remains, after all the needs for survival have crumbled, is either of panic or undirected and ludic; where everything that you do is either an action or is not carried out because any idea of planning for the future is impossible.

The turning-point for this second generation of new addicts who do not consider themselves real drug-addicts at all, is to be found in their search for the experience of a high (or a buzz) which leads them to use a mixture of drugs. The tragic outcome of the lifestyle of these polyabusers seems to confirm that human beings are not mature enough to live in complete freedom, where freedom also means being free from the symbolic forms that ritualise and ceremonialise all the ups and downs of life. At this point the drug addict, surpassing the narrow medical world, sets out the ontological problem of the freedom of man in the world.

The analysis that phenomenology carries out at the base of consciousness and of experience and of the addict's world, in this playing by ear, beyond the disintegration of categories, captures the eternal instant, the disappearance of the past as a memory and of the future as a project, the transformation of cyclical time into linear time. The drug addict's craving after a meaning among the ruins left behind by his addiction, almost caused by the emptiness of non-sense, is met. The doctor and the patient, both wayfarers among the ruins of the world, become travelling companions in the difficult search for a meaning which at this point has become a common objective

From the phenomenological point of view, the addict appears as a tragic figure devoured by his own boundless appetite, dominated by a grandiose and unlimited picture of himself, condemned to forever follow his erratic consciousness. He will continuously and without success keep searching in the crepuscular nirvana of the high for his lost presence, profoundly and irredeemably damaged in its emphatic relation with the world, exposed to the 
misery of its continuous failure and faced with the insignificance of everyday reality compared to his artificial paradise.

Today, while the more accredited approaches appear to be experiencing increasing difficulty, the phenomenological approach permits the doctor to work in conditions that allow him to have satisfactory visibility of both the patient and of his path to recovery, as well as allowing him to apply himself successfully to the continuing relationship while at the same time maintaining contact with the patient despite the inconstancy and the chronicity of the various problematic situations. Once again "treatment", "the world", "the project", "lived space", "lived time", "the situation", "the lived body", "conscience", "destiny" and "freedom" are all essential in order to enable any kind of favourable encounter with anyone who, like all addicts, has either lost himself completely or is in the process of doing so. Borgna, in 1978, published a seminal paper entitled "La tossicomania come esperienza psicoterapeutica - Drug addiction as a psychotherapeutic experience", in Psichiatria Generale e dell'Età Evolutiva, which is of extraordinary relevance. Indeed, it can be considered the groundwork for all subsequent research on the subject. The essential aspects of this paper can be summarised as follows:

1) Drug addiction as an experience that is deeply inherent to the human experience. Or rather, drug addiction seen as a possibility inscribed in the destiny of every one of $u s \ldots$

3) Being able to relate to the drug addict is only possible outside the professional role and after having abandoned every certainty.

4) The discovery in the drug addict's world of a distinctive feature of our time: the loss of the sense of the world.

An article entitled "L'esperienza del Leib sessuale nei tossicodipendenti - The experience of the sexual Leib in drug addicts" by Callieri appeared in the journal Attualità in Psicologia in 1993.

"It seems to be the case that the heroin-addicts are lacking in any ability to effectively plan their lives because they consider their bodies simply as being an obstacle, or rather, as an inexhaustible source of urgent needs. They can remain a presence, while rarely taking part" (Callieri, 1993). Thus, the physical body (Koerper) takes the place of the lived body (Leib) in drug addicts, and all meaningful communication with others breaks down, leaving room only 
for the barest of superficial exchanges. The addict's sexuality tends to remain within the closed circle of being-high and functions in the present living exclusively for the next fix. The encounter for the body-I-have is reduced to a mere risk. The body is at the disposal of another body, occasional epiphenomenon of life/existence. What is missing entirely is 'that which is beyond', the encounter with another body seen as one's own opening up towards the other body. The osmosis between sexuality and existence is completely absent here due to the coagulation or even cicatrizing effect of craving (the compulsive desire for drugs). It is almost as if a single longing has summed up and absorbed all the others resulting in the loss of We-ness.

\section{Addictive being-in-the-world: general features}

The world-of-life of drug-addicts is conditioned by the presence or absence of narcotic substances. These substances, or the behaviour resulting from drug abuse while they are being used, totally absorb the patient's intentional consciousness and modify its spatialtemporal structure. Since the patients during their lives are not always under the influence of drugs, or totally involved with their addiction, it follows that their state of intentional consciousness varies according to how much the object of their addiction has influenced their lived experience/life. Therefore we can summarize the way in which the patients experience addiction fundamentally in the following three dimensions:

1) When the patient is directly under the effect of drugs or when his resulting behaviour is caused by the addiction.

This is a passive dimension in which the subject is passive. Whereas in normal conditions we have a fluid intentionality and our common sense is the obviously pre-reflexive result of this situation, under the influence of a drug intoxication we lose this intentional stability (Selbstverstaendlich) and, as a result, suffer from a kind of intentional instability, which we can identify with the term floating world.

2) When the object of addiction is not present.

This is the phase of abstinence or craving, and is characterised by the lack of the substance and the resulting irrepressible longing to have it. In this phase the patient undergoes an intentional polarisation, which is both absolute and specific, on how to get his hands on the drugs again. The addict's purpose is polarised by his desired objective. Everything else is excluded or considered only as tools which can help achieve the final goal. 
3) When the patient is desensitized to the substance or the additive behaviour.

This is the phase when the problem becomes chronic, in which the effects of the addictive behaviour have faded, though the patient is not yet able to live a normal life. He is apathetic, indifferent, abulic, lacking in will-power and the world seems grey to him. This is the dimension of the frozen world-of-life.

\section{The twilight consciousness}

What precisely do addicts mean when they say: "I am high?" What is the psychopathological meaning of this state of consciousness which for them represents a sort of steady-state? Cargnello, Callieri and Morselli (1962) described a condition of "twilight calm" in subjects who experienced LSD, after the hallucinatory state. On these bases, we can considerer the experience of a high as an equivalent of the twilight state of consciousness. In the classic description by Jaspers (1959) and Schneider (1959), the twilight state of consciousness is a restriction of the field of consciousness. In the twilight state of consciousness there is no dramatic alteration of arousal. The field of consciousness, furthermore, can still spread itself. The twilight state of consciousness is a sort of threshold between the light of reality and the shadow of dream and psychosis. The twilight state of consciousness promotes illusions, delusions, hallucinations. De-personalisation and derealisation are normal experiences in the twilight state of consciousness, in which it is more likely that Klosterköetter (1988) transitional phenomena occur, from basic symptoms to final phenomena (Gross, Huber \& Klosterköetter, 1987). Addicts experience this vulnerable condition every day, every month, every year. The perception of reality in addicts is discontinuous, incomplete and this twilight state becomes a sort of normal way of life. This state of consciousness is like a display that is continuously turned on and off, short flashes appear and disappear. Because of instability the twilight state becomes a transitional state. 


\section{Eyelids like a setting sun: into the floating world-of-life}

La lumière liquide parait pénetrér la surface des choses et entrer dedans

G. Flaubert

Making eye contact with a drug addict who has taken drugs inevitably reveals his eyes to be "les yeux en coucher de soleil". In that instant, while his experience has been swallowed up by the nirvana of the flash or the kalaidoscopic dizziness of a high, we who are standing in front of him, no longer exist for him. The world tends to disappear. His intentionality is completely 'floating', the world around is only perceived weakly and intermittently. There is no longer any noema present in the patient's awareness, only a noesis which melts into the hazy line on the horizon. On the other hand the fantastic interior experience is sharply in focus and, if sedatives are involved, there is a kind of fusion with the ocean, while if stimulants are used there is a kaleidoscope of shining photons and hypercolours. The floating world is characterized by splitting, vibration and a multiplication of images which can be both sequential or overlapping. There exists a violent twilight state of consciousness in patients who are suffering from the effects of drugs and are, consequently, in the situation of a floating world. Their lived body has become disjointed. Their senses have started to become something like a wild kaleidoscope. The lived space is haemorrhagic and the perception is of a loss of space, of being nowhere. Lived time is liquid and indefinite. "Life appears as if it were only a moment, freed and released from the present and the future" (Beringer, 1927).

There is no present, no past, no future. Having lost the connection of interior time all the drug addict has left is the transient moment of satisfaction. However, no sooner has the drug addict achieved a moment of pleasure than it suddenly vanishes and he is condemned to impulsive and compulsive repetition. When the patient experiences a high, he feels so absorbed in the present that he is no longer able to see the future. No longer being able to experience the past and having lost touch with the future the patient ends up being unable to grasp the present. "The addict is trapped in this repetition with no chance of moving forward" (V. von Gebsattel, 1954). The instantaneity, the pure instant, is the gap between the last dose and the next one: the liquid instant of "the high" rules. The moment of altered consciousness and the time of the depthless instant dominate everything else. Thus, the patient is trapped in a sort of circular liquidity of lived time, and suffers the pure illusion of linear movement. 
This state of consciousness or this way of being can overlap with a maniacal state, although they are in fact very different conditions. The maniac appears hyperactive, while the addict is passive during this moment of bliss. The instant that the drug addict experiences is dilated and swallows both past and future, while that of the maniac is an instant that is being continually projected into the future freed from the past. The maniac feels himself as being omnipotent, while the drug addict wallows in a feeling of blissful impotence.

\section{Into the world of craving}

What exactly happens in the state of acute drug deprivation? The acute withdrawal (the "cold turkey" syndrome) is a state of real discomfort. The patient's existence is centred around where the pusher is - the exact square, the road, the underpass. An acute and intolerable sense of emptiness continues to get ever more urgent. Anger, irritability, and loneliness are the dominant emotions that inundate the addict's state of mind There is a contrast between the cold space of substance craving which can be defined with the word "absence", and the hot space of substance enjoying which can be defined with the word "presence". When the patient experiences craving both past and future have been lost. The past is reduced exclusively to "the last time in which I have taken drugs". Everything is manipulated and everyone is reduced to just being an obstacle in the way of the addict's only remaining relationship - with the drugs he takes. The relapse and the nostalgia are strictly related to the experience of craving. The memory of the pleasure deriving from the drug is unforgettable. Intentionality, in this experience of craving, is totally directed to the search for substances. All the behaviour is drug oriented. Generally the patient is very active in order to find the drug as soon as possible. They always need more and more substances in order to feel themselves still alive. Often only a relapse can represent the way out from this terrible condition. Circular time is the temporal structure of craving: a chain which links the past and the future, continually displacing the past into the future, the future into the past. 


\section{Like snowmen: into the frozen world-of-life}

Then take me disappearin' through the smoke rings of my mind/ down the foggy ruins of time/ far past the frozen leaves... / Let me forget today until tomorrow Bob Dylan

On the other hand, following chronic drug assumption, which results in the desensitisation of substances, we have a sort of an intentional dramatic seizure of the world, which we can call the frozen world. In the encounter with a chronic addict an examiner will encounter the following: an empathy failure; boredom, emptiness; lack of meaning; loneliness; isolation.

The lived time, space, body and other existential parameters differ enormously in comparison with the same parameters of the floating world. In the latter, following chronic intoxication, the patient's consciousness becomes viscous, and the lived body is blocked now he finds himself in the state we call the frozen world. The body is modified at a neurobiological level by a chemical graft which inserts a relevant new artificial element into the lived body. The object body (Koerper) is the vehicle of powerful substances which can successfully alter all sensations and perceptions, and the whole world experience, reducing the addict's self into nothing more than a denatured, mineralized body (Koerper-ding). His intentionality is coagulated, time is insular and has been reduced to a pure frozen present without past and without future until the complete loss of the passing of time is experienced others have become unattainable objects which are lifeless, like unattainable distant snowmen. Tragically these patients become mere bystanders to their own existence. In order to feel themselves still alive they need more and more substances. But after years and years of addicted life, the effect of those substances has started to wear off. There is tolerance, habit, ineffectiveness, along with a progressive destruction of both the existential background and the existential network, as well as a development in progressive psychopathology and brain injury. Being-in-nothingness can became the typical state of addicts in the frozen condition. In this case, the frozen condition has become a sort of terminal point in the existence of addicts. 


\section{The paradise lost: the death of the feeling}

Mais la tristesse en moi monte comme la mer Baudelaire

It is necessary to differentiate this state from other ordinary states of depression. In fact, if we examine "depressive states" in addicted people a paradox emerges: does something like "depression" in addictive persons actually exist? We find several depressive-like conditions: the end of the "honeymoon", the chronic state of abstention, the chronic abuse as the drug becomes increasingly ineffective. In these conditions the addict's life is meaningless, without colours, without taste, without smell, without emotions. The chronic pain of the addict is not the same thing as depression. In addiction, the end dose of methadone or buprenorphine puts the patient in an uncomfortable situation. During psychotherapeutic treatment the patient can encounter a lack of motivation, on the other hand during community treatment or in prison, these patients, deprived of drugs, appear/result as very similar to patients suffering from depression. When the patient manages to resist a relapse he lives a sort of depressed lucidity: this is the sign of detoxification. The structure of a lived-time experience in these addiction-related situations is completely different from the structure of lived-time in normal life and in a depressive experience. In depression the lived-time is trapped in an irremovable past, which blocks the flow of time toward the present and the future. In these addicted-related conditions the essential characteristic is the reduction of the present into an island without past and without future. The final collapse of the addictive "Dasein" is a sort of being-in-nothingness. The crisis of the temporal-spatial vortex eventually and inevitably leads to the 'blow of the void' (le coup de vide): the experience of unreality or no self-experience. The total collapse of the world is the common final destination/ result of the breaking down of the temporal and spatial structure of "being-there" ("Dasein") (Binswanger, 1958). All addictions lead to the final collapse of the Being-in-theworld-with-others structure, and many addicts remain without the spatial-temporal dimension, thus making it virtually impossible for them to stay in a space-with-others and to project themselves in time. 


\section{The therapeutic encounter with the drug}

A doctor who meets an addict has to be completely without any prejudices and has to do his best to make contact both with the emotional nucleus of the person he has in front of him and with the "drug experience". This has to be done at the same time, though separately. The person who is talking in front of him is not merely a person who is a patient, he is also in a certain sense the drug itself. The doctor, therefore, makes contact both with the person and with the drug. The first thing he has to do is to make the drug into something akin to an experience endowed with a sense. The relationship that exists between the patient and the drug to which he is addicted is not a relationship between a free mind and a free object. The bond that ties the drug addict to the drug represents a curvature/distortion both of time and space, which is able to deform his whole world. Whatever idea the doctor has as regards the drug, it cannot in any way coincide with the drug the patient describes. If the doctor does acquire an adequate understanding of the substance in question and manages to look at it, at least in part, with the eyes of his patient, and in part with his own ability at eidetic vision, he cannot avoid sharing a respect for the drug in a similar way to the psychiatrist who respects the delusion when his patient finally makes it clear to him. This explication or revelation of the delusion is always a gift that the patient makes to the doctor, it is the revealing of a hidden secret. The doctor must not forget that the patient has dedicated a great part of his life to the drug in question, ending up with having emptied himself out completely because of it. The drug is an overwhelming passion, a total and exclusive love, to which the patient has given everything. He has nothing else and he is nothing else. Having completely identified himself with the drug he has inevitably cancelled himself out. He has thrown himself headlong into it just as a man can throw himself into the void. The drug is the precipitate of the last identity that the patient has left. If the drug has become a mask, then the patient has in turn become the drug. This means that if we want to talk about the drug then we have to talk about the patient's self. Nothing at all can come between the patient and the drug. They coincide with each other. The subjectivity of the patient has disappeared. Only the meeting with the doctor can demarcate the boundary between the subject and the drug. The doctor's first task is to create an epoché (a bracketing or suspension) once he has stopped considering the drug merely as a chemical agent and has started to consider it as a vital element: the element that characterises the addict's world-of-life, his Lebenswelt (Binswanger, 1973). The drug, therefore, represents the meeting place. It follows then that the objective is that of creating 
this together with the patient, or rather, to re-create this together in order that a part of the subjectivity of the doctor contaminates the remaining subjectivity of the patient.

The patient should stand up at the end of the meeting feeling that he has been speaking to someone who has finally understood the drug, and has therefore stopped underestimating it. The idea the patient has of the drug and remains with him after he has left the doctor is no longer the same idea he had before meeting the doctor. It is an idea of the drug that remains powerful, but also necessarily includes fragment of the other person's idea. If the doctor has been able to create in his own consciousness the idea of the drug through the eyes of the patient, then, in a collateral way, the patient cannot avoid finding himself having a new idea of the drug as seen through the doctor's eyes. This is something that never occurred during the pseudo-sharing experience with other drug addicts. As a result of this the first crack will appear in the dyadic-symbiotic drug-patient crystal, with the introduction of the doctor's subjectivity. At this point the patient starts to feel confused, while at the same time a newly kindled desire to meet the doctor again will start to appear. A wish to see that person again who had made the addict feel something new. That presence (Dasein) which has caused this new sensation. Deep down the addict still remains on the hunt for feelings. Meanwhile the doctor will have managed to wrongfoot his patient's prejudice with regard to all those people who don't take drugs and are therefore not able to understand him. In this way the doctor has succeeded in initiating a process that is the opposite of the action of the drug over the patient: drugs mineralise/petrify a patient's consciousness making it inorganic/lacking in coherence/disorganised while the doctor subjectifies the drug, makes it coherent/organised, he responsibilises it, he dualises it, he makes it become human, he humanises it, thus successfully reclaiming a part of the patient for humanity (Zutt, 1963). This resurfacing of the 'you', purposefully triggered in the patient's 'ego' by the doctor, troubles/agitates/upsets the patient so much so that it almost achieves an effect comparable/similar to that of the drug itself.

Most importantly of all the doctor should be ready to hem in the void, to reach the core of the patient's life, because that is where anything that is left of the patient (even if it is nothing more than an inner strength) can still be found. This phenomenology of the first contact is experienced with great intensity, and which continues after the encounter, also out of the setting, has been called "point blank phenomenology" (Di Petta, 2004). Basically, it is about entering into the inclination of the other person, in other words being able to make a 
direct contact. This is made possible above all through the use of one's own personal resources rather than professional ones, and yet runs the risk of losing the patient through having revealed yourself rather than losing him anyway though remaining within the norms. For this to be successful it is necessary to have already achieved great freedom of movement, which in turn derives from an extremely disciplined training.

\section{A lived time Psychotherapy: the Dasein-group analysis}

The phenomenological-existential approach is first and foremost philosophical, and it is based on philosophical thinkers such as Buber, Dostoievsky, Frankl, Heidegger, Husserl, Jaspers, Kierkegaard, Nietzsche, Sartre, Tillich and others. It is concerned with the understanding of people in relationship to the world in which they live and with the individual's search for what it means to be alive. It is committed to exploring questions about living and dying. Dasein-group analysis (Di Petta, 2006) represents a further development in the theoretical phenomenological and existential frame applied to addicted patients who are also mentally ill. Dasein-group analysis is a powerful form of therapy that focuses on concerns rooted in human existence, giving movement to the blocked time the addicts suffer. Pathicity (Straus, 1930, 1978) allows an access into the patient's time experience (Minkowski, 1971). This phenomenological approach to the psychotherapy of addicts has been applied ${ }^{1}$ in those addiction centres with everyday contact with patients, and has always given rise to an intense emotional atmosphere ${ }^{2}$. In many of these patients the human sense of identity is lost even where there is no psychotic symptomatology. In these cases the only way to survive is to achieve vital contact with another person, feeling empathy for the emotional, affective dimension of another person. The "epoché" (Husserl, 1965) is the preliminary condition of this setting. Especially when this requires the doctor to abandon his own role.

\footnotetext{
${ }^{1}$ One of the most important ideas of phenomenology, in fact, is the deep union between the subject, other people and the world-of-life. This idea offers an enormous transforming potentiality, which is very useful in a modified setting of group psychotherapy.

${ }^{2}$ This idea of a plural phenomenology (being-we-in-the-cure), the realization of Binswanger's wenesswhich-loves (1942), in an emotional group made up of doctors and patients together, was a result of hopelessness due to failed encounters with the addicts' existences. The intention was to offer a common and intimate place, a new space, a new time, in which anyone was able to have the chance to feel his or her own existential condition completely. The chance to feel one's own body again and that of another, the possibility to feel one's own pain again and that of others, to feel the support of others, the possibility to cry one's heart out. Among some of these lost existences this new phenomenological approach has become a sort of way out, which through cure can eventually lead to freedom and the world.
} 
The lived experiences mix freely in a totally emotional context. Subsequently within the group the shared emotions reveal a truly meaningful lived dimension, made up of pain and pleasure, helplessness and happiness, loneliness and nearness, anger and friendship: a sort of “fundamental affective position" (Heidegger's Befindlichkeit, 1927). This group approach is centred on the search for an authentic inter-subjective encounter, as the crucial embodied event. This condition, which happens face-to-face between two human beings in the middle of the group, is the necessary step for any subsequent cure ${ }^{3}$. The phenomenological background has been extremely useful especially in the close encounter (face-to-face) with the patient, who is respected more as a real person than as just another clinical case. The lived experience, here, (any lived experience including delusional or hallucinatory experiences) has its own intentionality (aboutness). These experiences in the emotional context of the phenomenological group freely mix with each other, producing change and transformation in all participants. The passage from initial negative emotions to final positive emotions in each group session is crucial. It is like a journey from helplessness to hope, from pain to light, from loneliness to intimate nearness. The therapist here is not outside the group, but completely inside $i t^{4}$. Both the therapist and the patient abandon their roles and are in the phenomenological group as human beings body-to-body, existence-to-existence, as persons who love, cry, feel, without the barrier that exists between therapists and their patients. From being one-next-to-another (Nebeneinandersein) and from being one-in-front-of-another (Voreinandersein) to being-one-with-another (Miteinandersein). This gives them the chance to live in a space and time in which it is not important to answer the question "who am I?", but the question "what do I feel"? and "how do I feel"?5. Starting from a common emotional

\footnotetext{
${ }^{3}$ This phenomenological approach to group therapy is quite different from the psychoanalytical approach to group therapy. In fact it is based on consciousness and not on the unknown. The phenomenologist sees the essence of phenomena. He does not use interpretation. Whereas the psychoanalyst is more interested in recording the hidden meanings beyond the phenomena.

${ }^{4}$ An evident difference when compared to psychoanalysis is the complete involvement of the therapist as a human being in the emotional dimension of the group, in the same way and on the same level as the patient.

${ }^{5}$ As the group therapist in a Dasein-group session I feel myself to be in search of a starting point from somewhere within my own personal experience in order to begin the group therapy (Di Petta, 2004). In the penumbra of a deep silence I am waiting for an intuition in my mind. Within the experience of my consciousness of the world of life (Lebenswelt) I find the concrete inter-subjectivity of the participants. This has specific colour, form, smell, sound. The initial silence within the group is complete. This pregnant silence is the necessary prelude to the group therapy. What can I say about this special silence? What is this deep silence? I can feel the emergence of the anxiety of waiting in this silence. I can see the
}

Psicopatologia Fenomenológica Contemporânea, 2017;6(1):15-36 
hinterland, in which we can find our lost parts, in which we can give to others the parts they have lost, in which we can find our own internal experience, and in which there is the chance to look for and discover these parts which are still alive ${ }^{6}$. The group participation is open to everybody, no matter what his condition. Anyone from anywhere is admitted to this new kind of group. At the end of the group session it is evident that not even heroin is able to calm anyone more than a warm hug between two human beings; and that life itself is a greater excitement than cocaine.

From a phenomenological point of view, the form (i.e. essence or eidos) of the lived experience (pathos) is crucial. The form of lived clarifies itself. Sometimes the people who meet each other in the centre of group. The atmosphere changes and gradually becomes more positive. The internal pain and anguish become hope and light. The lived experience (Erlebnis) recalls another lived experience, becomes another lived experience, looks for another lived experience (Binswanger, 1957). If it is authentic, it is also therapeutic. At the end of the group session all the participants feel harmony. The therapist concludes speaking about his own lived experience. Two hours have passed. Someone is still crying silently. The mixture of pain, anger and helplessness has led to a feeling of relief. We may legitimately wonder at this point how it has been possible to achieve positive emotions, having started off with negative ones. Is it not, perhaps, the World-of-life (Lebenswelt)?

profiles of the faces, I can see the eyes, the bodies of everyone. I speak with simple words about my own lived experience, what I have in my heart and I use words from the heart. I am the doctor, the group leader, but at the same time I am the first patient of the group. I talk about what I am feeling simply, authentically as an ordinary human being at that moment: my anger, my pain, my tiredness, my shame, my guilt.

${ }^{6}$ Beyond the language of medicine and psychology the essence of psychotic experience, for example, remains something that cannot be explained, even if it is possible to perceive it. Phenomenological language in this case must adapt itself to the heart of the lived experience.

Psicopatologia Fenomenológica Contemporânea, 2017;6(1):15-36 


\section{References}

Beringer, K. (1927). Der Mescalinrausch. Berlin: Springer.

Binswanger, L. (1973). Essere nel mondo. Roma : Astrolabio.

Binswanger, L. (1957). Daseinsanalyse und Psychotherapie. Speer, Zurich: Aktuelle Psychotherapie.

Binswanger, L. (1958). Daseinsanalyse, Psychiatrie, Schizophrenie. Conferenza in lingua tedesca e inglese tenuta a Zurigo al II congresso internazionale degli psichiatri. Schweiz. Arch. Neurol. Psychiat., LXXXI, 1/2, 1958; trad.it. di Esposito S., in Attualità in psicologia, 18, 3-4, 2003, 197-204.

Borgna, E. (1978). La tossicomania come esperienza psicoterapeutica, Psichiatria Generale e dell'età evolutiva, I, 127-137.

Callieri, B. (1993). L’esperienza del Leib sessuale nei tossicodipendenti. Attualità in Psicologia, 8, 5-9.

Cargnello, D., Callieri, B. \& Morselli G. E. (1962). Le psicosi sperimentali. Milano: Feltrinelli.

Di Petta, G. (2004). Il mondo tossicomane, fenomenologia e psicopatologia. Milano: Franco Angeli.

Di Petta, G. (2006). Gruppoanalisi dell'esserci: tossicomania e terapia delle emozioni condivise. Milano: Franco Angeli.

Gebsattel, V. E. (1954). Prolegomena einer medizinschen Anthropologie. In Zur Psychopathologie der Sucht (pp. 220-227). Berlin: Springer.

Gross G., Huber G., Klosterköetter J. \& Linz M. (1987). "BSABS. Bonner Skala für die Beurteilung von Basissymptomen”. Berlin-Heidelberg-New York: Springer.

Heidegger, M. (1927). Sein und Zeit. Tubingen: Niemeyer.

Husserl, E. (1965). Idee per una fenomenologia pura e per una filosofia fenomenologica. Torino: Einaudi.

Jaspers, K. (1959). Allgemeine Psychopathologie. Berlin: Springer.

Klosterköetter, J. (1988). Basissymptome und Endphänomene del Schizophrenie. Berlin: Springer.

Minkowski, E. (1971). Il tempo vissuto. Fenomenologia e psicopatologia. Torino: Einaudi.

Schneider, K. (1959). Psicopatologia clinica. Tr. it. Roma: Città Nuova.

Straus, E. (1978). Geschehenis und Erlebnis. Berlin: Springer. 
Straus, E. (1930). Vom Sinne der Sinne. Berlin: Springer.

Weizsaecker, von V. (1978). Der Gestaltkreis Theorie der Einheit von Warnhemen und Bewegen. Stuttgart: Georg Thieme.

Weizsaecker, von V. (1967). Pathosophie. Goettingen: Vandenhoeck \& Ruprecht.

Zutt, J. (1963). Zur Anthropologie der Sucht. In Auf dem Wege zu Einer Anthropologischen Psychiatrie (pp. 423-430). Berlin: Springer. 